INTERSTITIAL LUNG DISEASE

\title{
Incidence and mortality of idiopathic pulmonary fibrosis and sarcoidosis in the UK
}

\author{
J Gribbin, R B Hubbard, I Le Jeune, C J P Smith, J West, L J Tata
}

Thorax 2006;61:980-985. doi: 10.1136/thx.2006.062836

See end of article for authors' affiliations

Correspondence to Correspondence to:
Professor R Hubbard, Respiratory Medicine Clinical Sciences Building, City Hospital, Hucknall Road, Nottingham NG5 IPB, UK; Richard. Hubbard@nottingham.ac. uk

Received 20 March 2006

Accepted 21 June 2006

Published Online First

14 July 2006
Background: Idiopathic pulmonary fibrosis (IPF) and sarcoidosis are common diagnoses in patients attending chest clinics, but little is known about the epidemiology of these diseases. We used data from a general practice database to provide information on the current incidence of IPF and sarcoidosis in the UK. Methods: Data were extracted for all patients with a diagnosis of IPF or sarcoidosis between 1991 and 2003. The whole population of the database was used to calculate disease incidence stratified by age, sex, region, and time period. Poisson regression was used to compare the incidence between populations and Cox regression was used to compare survival between populations.

Results: 920 cases of IPF (mean age 71 years, 62\% male) and 1019 cases of sarcoidosis (mean age 47 years, $47 \%$ male) were identified. The overall incidence rate per 100000 person-years was 4.6 for IPF and 5.0 for sarcoidosis. The incidence of IPF increased progressively between 1991 and 2003 $(p<0.00001)$, and was highest in Northern England and Scotland $(p<0.0001)$. The survival of patients with IPF was stable over time. In contrast, the incidence of sarcoidosis was highest in London, West Midlands and Northern Ireland and remained stable over time.

Conclusions: The incidence of IPF has more than doubled between 1990 and 2003; this is not due to the ageing of the UK population or an increased ascertainment of milder cases. The incidence of sarcoidosis has not changed during this time period. Our findings suggest that more than 4000 new cases of IPF and 3000 new cases of sarcoidosis are currently diagnosed each year in the UK.
C aring for patients with interstitial lung disease is an important part of the work load of chest physicians, yet little is known about the epidemiology of these diseases. ${ }^{1}$ Idiopathic pulmonary fibrosis (IPF) and sarcoidosis are generally thought to be the most common interstitial lung diseases, but the lack of basic information on disease frequency and associated mortality has been an important barrier to the planning of services for these patients. The currently available estimates of disease incidence in the UK come mainly from studies in the early 1990s which show that about 1500 people die each year from IPF, and that the number of death registrations increased progressively between 1979 and 1992. ${ }^{2}$ Information on the prognosis of patients with IPF comes from a number of different cohorts and has universally been found to be poor, with a median survival from diagnosis of 3-5 years and patients losing an average of 7 years of life. ${ }^{4-7}$ It is not known whether this poor prognosis has changed over time as more cases are diagnosed.

Estimates of the incidence of sarcoidosis are available from disease registries and health insurance datasets in the USA and these suggest that, in general, the incidence of sarcoidosis is lower than for IPF. ${ }^{8}$ There are few data available on the change in the incidence of sarcoidosis over time, however, and no recent data are available for the UK. In addition, sarcoidosis is generally regarded as a disease with a good prognosis and few data are available on the mortality associated with this disease.

We have analysed data from a computerised longitudinal general practice database called The Health Information Network (THIN) ${ }^{10}$ to estimate the incidence of IPF and sarcoidosis in the UK between 1991 and 2003, stratified by age, sex, and geographical region. In addition, we studied the survival of patients with IPF and sarcoidosis in comparison with the general UK population.

\section{METHODS}

The Health Improvement Network (THIN) is a computerised longitudinal primary care database which includes diagnostic and prescribing data recorded by UK general practitioners as part of routine clinical care and information from secondary hospital referrals. The data are derived from general practices which use the In Practice Systems Vision software and, in return for providing data practices which volunteer to contribute to THIN, receive help with software training and audit. The version of THIN used in this study includes information collected up to November 2004 from 255 general practices, and this represents about $25 \%$ of practices that were using Vision in the UK at this time. The demographic data of this population, which included an average of 1555152 people in each of the study years, were similar to those of the UK population. Each person in THIN has a start date defined as the later of their date of registration at the practice or practice date of computerisation, and a stop date defined as the earliest of either the last THIN data collection or the date of death.

Data from two "exposed" patient cohorts (one containing people with IPF and one comprising people with sarcoidosis) and two matched general population control cohorts were analysed. The term "IPF" was used to describe people who have a diagnosis that is made clinically because only a small minority of patients have an open lung biopsy. ${ }^{11}$ The Read Code (diagnostic terms) used to construct our look-up table to identify these patients were "cryptogenic fibrosing alveolitis" and "idiopathic fibrosing alveolitis", which reflect the clinical terms commonly used in the UK over the last 20 years. People were included in the IPF cohort if they had at least one recorded IPF diagnosis, their first IPF diagnosis was recorded at least 12 months after their start date, and they were aged at least 40 years when they received the first diagnosis. This definition was used to try to capture incident 
rather than prevalent cases and the age cut off was used to improve diagnostic specificity. We then selected a comparison cohort consisting of up to four general population controls per IPF patient, matched by age, sex and general practice and contributing data at the time the case had their first diagnosis of IPF recorded. A similar method was used to identify a cohort of people with incident sarcoidosis and a matched comparison cohort, although we did not use any age cut off.

\section{Data analysis}

For the incidence analyses the total THIN population was used as the denominator, calculating the mid-year population numbers for each year between 1991 and 2003 stratified by sex, UK region, and 5 year age band. Data for the years before 1991 were not used because the numbers were small, and data for 2004 were also not used because we did not have a complete year of follow up. Crude incidence rates for each disease were calculated and stratified by age, sex, and region. Poisson regression was then used to model disease incidence and to allow us to control for changes in the age and sex structure of the UK population over time. For these analyses, study subjects were grouped into 10 year age bands over the age of 55 years for IPF and over the age of 25 years for sarcoidosis, and calendar periods were grouped into approximately 4 year periods.

For the survival analyses, all deaths within the four cohorts were identified and Kaplan-Meier methods were used to calculate 3 and 5 year survival rates. Crude mortality rates were calculated for the cohorts and Cox regression was used to compare the mortality rates between disease and control cohorts, adjusting for the effects of age, sex, calendar period, and region.

STATA version 7 was used for all statistical analyses and likelihood ratio tests for all the hypothesis tests. The proportional hazards assumption for all the Cox regression models was checked using the diagnostic section within STATA. The study protocol was reviewed and approved by the Nottingham research ethics committee.

\section{RESULTS}

Nine hundred and twenty patients with IPF who were over the age of 40 years when they received their first diagnosis were identified, and 3593 matched controls. Nine patients in whom the diagnosis of IPF was first recorded under the age of 40 years were excluded. The mean (SD) age of those with IPF at presentation was 71 (11) years and 568 (62\%) were male. We identified 1019 cases of sarcoidosis and 4076 controls. The mean (SD) age of the patients with sarcoidosis was 47 (14) years and 483 (47\%) were male. The age distribution of cases is shown in fig 1.

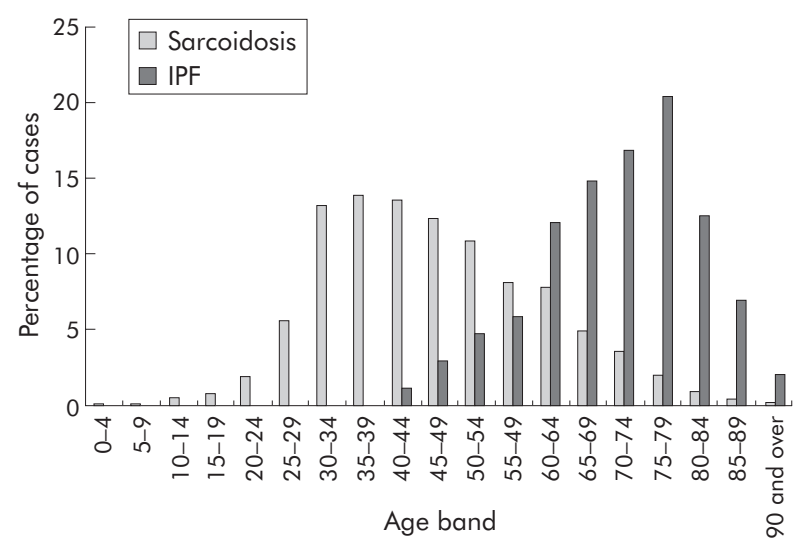

Figure 1 Age at diagnosis of patients with IPF and sarcoidosis.

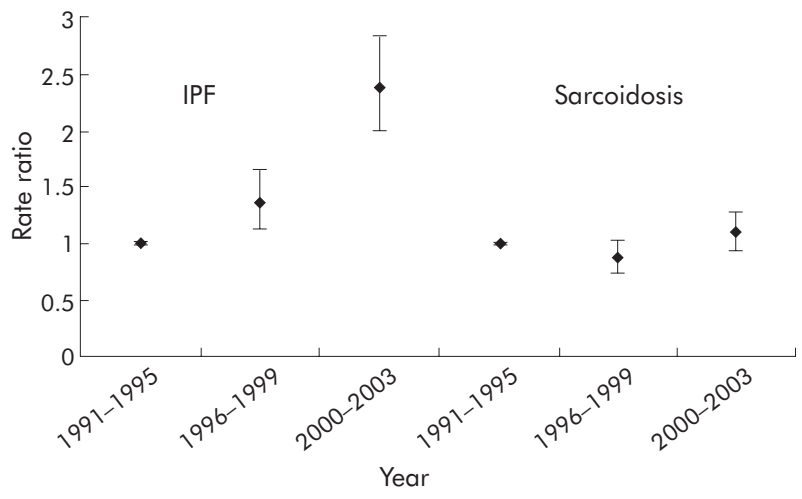

Figure 2 Trends in incidence of IPF and sarcoidosis over time; calendar period rate ratios adjusted for age, sex, and region of UK.

\section{Idiopathic pulmonary fibrosis}

Overall, the crude incidence rate for IPF was 4.6 (95\% CI 4.3 to 4.9 ) per 100000 person-years, and the rate was higher in men than in women and in older people (table 1). The crude rates also increased progressively over time and tended to be higher in the northern and western regions of the UK (table 1). Statistical analysis confirmed that the incidence of IPF has increased significantly over time, even allowing for the strong effects of age and sex (table 2, fig 2). To provide an additional estimate of the annual increase in the incidence of IPF, we repeated our analyses fitting year as a continuous variable. After controlling for the effects of sex, age and geographical region, we estimated the annual increase in the incidence of IPF to be $11 \%$ (rate ratio 1.11 , 95\% CI 1.09 to $1.13, \mathrm{p}<0.0001)$. There was no evidence of a statistical interaction to suggest that the trend in incidence over time was restricted to one particular sex or age group. There was also evidence of statistically significant heterogeneity between areas in the UK, with the highest rates in Scotland and the North and the lowest rates in the South East. The mean follow up period after diagnosis for patients with IPF was 2.7 years, and during this time $442(48 \%)$ died. In the comparison cohort, 613 (17\%) died during a mean follow up period of 3.9 years. The 3 and 5 year survival percentages for patients with IPF were $57 \%$ and $43 \%$ respectively, and the equivalent percentages in the comparison cohort were $88 \%$ and $81 \%$. Sufficient numbers of patients with IPF had died to permit calculation of the median survival time, which was 3.9 years. The crude mortality rate for people with IPF was 180 per 1000 person-years (95\% CI 164 to 198) and, after adjusting for the effects of sex and age, there was a marked increase in mortality in people with IPF compared with the comparison cohort (hazard ratio $4.49,95 \%$ CI 3.97 to 5.09 ). Within the group with IPF, male sex and increasing age were important determinants of survival, but no association was seen with calendar period or with region (data not shown for region, $\mathrm{p}$ value $=0.62$, table 3 ).

\section{Sarcoidosis}

Overall, the crude incidence rate for sarcoidosis was 5.0 (95\% CI 4.7 to 5.4) per 100000 person-years and, in contrast to IPF, the crude rates were similar in men and women and appeared to be stable over time. The highest incidence for sarcoidosis was between the ages of 35 and 55 years, and diagnoses were rare under the age of 25 and over the age of 75 years. The highest crude rates for sarcoidosis were in Northern Ireland and London (table 4), and these patterns remained after allowing for the effects of age, sex, calendar periods, and geographical region (table 5, fig 2). The mean follow up period after diagnosis for patients with sarcoidosis 
Table 1 Incidence rates for IPF

\begin{tabular}{|c|c|c|c|}
\hline & Cases & Person-years & $\begin{array}{l}\text { Crude incidence rate }(95 \% \mathrm{Cl}) \\
\text { per } 100000 \text { person-years }\end{array}$ \\
\hline \multicolumn{4}{|l|}{ Sex } \\
\hline Women & 352 & 10222173 & 3.44 (3.10 to 3.82 ) \\
\hline Men & 568 & 9986972 & $5.69(5.24$ to 6.18$)$ \\
\hline \multicolumn{4}{|l|}{ Calendar period } \\
\hline $1991-1995$ & 170 & 6233416 & $2.73(2.35$ to 3.17$)$ \\
\hline $1996-1999$ & 256 & 6693147 & 3.83 (3.38 to 4.32 ) \\
\hline $2000-2003$ & 494 & 7282582 & $6.78(6.21$ to 7.41$)$ \\
\hline \multicolumn{4}{|l|}{ Age group (years) } \\
\hline$<55$ & 79 & 14673667 & $0.54(0.43$ to 0.67$)$ \\
\hline $55-64.9$ & 166 & 2273994 & 7.30 (6.27 to 8.50$)$ \\
\hline $65-74.9$ & 290 & 1700126 & $17.06(15.20$ to 19.14$)$ \\
\hline $75-84.9$ & 302 & 1190302 & 25.37 (22.67 to 28.40$)$ \\
\hline$>85$ & 83 & 371056 & 22.37 (18.04 to 27.74$)$ \\
\hline \multicolumn{4}{|l|}{ Region } \\
\hline North East & 40 & 706845 & 5.66 (4.15 to 7.72$)$ \\
\hline North West & 135 & 2344317 & 5.76 ( 4.87 to 6.82$)$ \\
\hline Yorkshire and Humber & 32 & 908784 & 3.52 (2.49 to 4.98 ) \\
\hline East Midlands & 44 & 1121229 & 3.92 (2.92 to 5.27 ) \\
\hline West Midlands & 102 & 2140811 & 4.77 (3.92 to 5.79 ) \\
\hline East & 85 & 1790865 & 4.75 (3.84 to 5.87 ) \\
\hline London & 102 & 2769396 & 3.68 (3.03 to 4.47 ) \\
\hline South East & 131 & 3695545 & $3.55(2.99$ to 4.21$)$ \\
\hline South West & 85 & 1443767 & $5.89(4.76$ to 7.28$)$ \\
\hline Northern Ireland & 22 & 674326 & $3.26(2.15$ to 4.96$)$ \\
\hline Wales & 73 & 1409933 & $5.18(4.12$ to 6.51$)$ \\
\hline Scotland & 69 & 1203327 & $5.73(4.53$ to 7.26$)$ \\
\hline
\end{tabular}

was 5.4 years and that for the comparison cohort was 5.3 years. During this time, 78 patients with sarcoidosis (8\%) died compared with $163(4 \%)$ of the comparison cohort. The percentage of patients with sarcoidosis alive at 3 and 5 years was $95 \%$ and $93 \%$ respectively, and the equivalent values for the comparison cohort were $98 \%$ and $96 \%$. The crude mortality rate for patients with sarcoidosis was 14 (95\% CI 11 to 18) per 1000 person-years and, after allowing for the effects of age and sex, the mortality rate was approximately double that in the comparison cohort (hazard ratio 2.09, 95\%

Table 2 Poisson regression modelling of IPF incidence

\begin{tabular}{ll}
\hline & $\begin{array}{l}\text { Mutually adjusted incidence rate } \\
\text { ratios }(95 \% \mathrm{Cl})\end{array}$ \\
\hline $\begin{array}{l}\text { Sex } \\
\text { Women }\end{array}$ & 1.00 \\
Men & $2.13(1.87$ to 2.44$), \mathrm{p}<0.0001$ \\
Calendar period & 1.00 \\
1991-1995 & $1.36(1.12$ to 1.66$)$ \\
1996-1999 & $2.39(2.01$ to 2.84$), \mathrm{p}<0.0001^{*}$ \\
2000-2003 & 1.00 \\
Age group (years) & $13.50(10.33$ to 17.65$)$ \\
$<55$ & $33.44(26.07$ to 42.89$)$ \\
$55-64.9$ & $51.91(40.49$ to 66.55$)$ \\
65-74.9 & $49.91(36.60$ to 68.07$), \mathrm{p}<0.0001^{*}$ \\
$75-84.9$ & $1.84(1.29$ to 2.62$)$ \\
$>85$ & $1.90(1.49$ to 2.41$)$ \\
Region & $1.11(0.76$ to 1.64$)$ \\
North East & $1.30(0.93$ to 1.83$)$ \\
North West & $1.60(1.24$ to 2.08$)$ \\
Yorkshire and Humber & $1.44(1.09$ to 1.89$)$ \\
East Midlands & $1.34(1.03$ to 1.73$)$ \\
West Midlands & 1.00 \\
East & $1.42(1.08$ to 1.87$)$ \\
London & $1.18(0.75$ to 1.86$)$ \\
South East & $1.63(1.22$ to 2.17$)$ \\
South West & $1.85(1.38$ to 2.48$), \mathrm{p}<0.0001$ \\
Northern Ireland & \\
Wales & \\
Scotland & \\
\hline All incidence rate ratios are mutually adjusted for all other variables in \\
the table. \\
* p for trend.
\end{tabular}

CI 1.59 to 2.74). Within the group with sarcoidosis, male sex and increasing age were associated with increased mortality, but there was no association with calendar period or geographical region (data not shown for region, $\mathrm{p}=0.64$, table 6).

\section{DISCUSSION}

We have found a progressive increase in the incidence of IPF between 1991 and 2003 which is not explained by the aging of the UK population. The incidence of IPF was higher in men, older people, and in Northern England and Scotland. The prognosis of patients with IPF in our cohort was poor, in keeping with previous studies, ${ }^{457}$ but remained stable over time. This suggests that the increase in disease incidence we observed was not due to an increased ascertainment of milder cases. On the basis of our findings, we expect at least 4000 cases of IPF to be diagnosed annually in the UK over the next few years, and that this figure could increase further. Overall, the incidence of sarcoidosis was similar to that for IPF but did not increase over time. The incidence of

Table 3 Survival analysis for patients with IPF

\begin{tabular}{ll}
\hline & $\begin{array}{l}\text { Mutually adjusted hazard } \\
\text { ratios }(95 \% \mathrm{Cl})\end{array}$ \\
\hline Sex & \\
$\begin{array}{l}\text { Women } \\
\text { Men }\end{array}$ & 1.00 \\
$\begin{array}{c}\text { Calendar period } \\
\text { 1991-1995 }\end{array}$ & $1.40(1.15$ to 1.70$), \mathrm{p}=0.001$ \\
1996-1999 & $0.86(0.67$ to 1.11$)$ \\
2000-2003 & $0.92(0.71$ to 1.19$), \mathrm{p}=0.6^{*}$ \\
Age group (years) & 1.00 \\
$<55$ & $2.25(1.30$ to 3.91$)$ \\
$55-64.9$ & $3.30(1.96$ to 5.56$)$ \\
$65-74.9$ & $5.25(3.13$ to 8.81$)$ \\
$75-84.9$ & $8.75(4.98$ to 15.36$), \mathrm{p}<0.0001^{*}$ \\
$>85$ &
\end{tabular}

All incidence rate ratios are mutually adjusted for all other variables in the table.

* $p$ for trend. 


\begin{tabular}{|c|c|c|c|}
\hline & Cases & Person-years & $\begin{array}{l}\text { Crude incidence rate }(95 \% \mathrm{Cl}) \\
\text { per } 100000 \text { person-years }\end{array}$ \\
\hline \multicolumn{4}{|l|}{ Sex } \\
\hline Women & 536 & 10222173 & 4.84 (4.42 to 5.29$)$ \\
\hline Men & 483 & 9986972 & $5.24(4.82$ to 5.71$)$ \\
\hline \multicolumn{4}{|l|}{ Calendar period } \\
\hline $1991-1995$ & 314 & 6233416 & $5.04(4.51$ to 5.63$)$ \\
\hline 1996-1999 & 298 & 6693147 & 4.45 (3.97 to 4.99$)$ \\
\hline $2000-2003$ & 407 & 7282582 & $5.59(5.07$ to 6.16$)$ \\
\hline \multicolumn{4}{|l|}{ Age group (years) } \\
\hline$<25$ & 33 & 5948510 & 0.56 (0.39 to 0.78$)$ \\
\hline $25-34.9$ & 191 & 2968386 & $6.43(5.58$ to 7.42$)$ \\
\hline $35-44.9$ & 281 & 3157466 & $8.90(7.92$ to 10.00$)$ \\
\hline $45-54.9$ & 236 & 2599305 & 9.08 (7.99 to 10.32 ) \\
\hline $55-64.9$ & 160 & 2273994 & 7.04 (6.03 to 8.22 ) \\
\hline $65-74.9$ & 87 & 1700126 & $5.12(4.15$ to 6.31$)$ \\
\hline $75-84.9$ & 28 & 1190302 & 2.35 (1.62 to 3.41 ) \\
\hline$>85$ & 3 & 371056 & 0.81 (0.26 to 2.51 ) \\
\hline \multicolumn{4}{|l|}{ Region } \\
\hline North East & 30 & 706845 & 4.24 (2.97 to 6.07$)$ \\
\hline North West & 88 & 2344317 & 3.75 (3.05 to 4.63 ) \\
\hline Yorkshire and Humber & 42 & 908784 & 4.62 (3.42 to 6.25 ) \\
\hline East Midlands & 55 & 1121229 & 4.91 (3.77 to 6.39 ) \\
\hline West Midlands & 118 & 2140811 & $5.51(4.60$ to 6.60$)$ \\
\hline East & 85 & 1790865 & 4.75 (3.84 to 5.87 ) \\
\hline London & 174 & 2769396 & $6.28(5.42$ to 7.29$)$ \\
\hline South East & 167 & 3695545 & 4.52 (3.88 to 5.26 ) \\
\hline South West & 74 & 1443767 & $5.13(4.08$ to 6.44$)$ \\
\hline Northern Ireland & 52 & 674326 & 7.71 (5.88 to 10.12 ) \\
\hline Wales & 72 & 1409933 & 5.11 (4.05 to 6.43$)$ \\
\hline Scotland & 62 & 1203327 & 5.15 (4.02 to 6.61$)$ \\
\hline
\end{tabular}

sarcoidosis was highest in London, the West Midlands, and Northern Ireland. Only a few deaths occurred in the sarcoidosis group, reflecting the younger age of this cohort, but survival was worse than that for the general population.

\begin{tabular}{|c|c|}
\hline & $\begin{array}{l}\text { Mutually adjusted incidence } \\
\text { rate ratios }(95 \% \mathrm{Cl})\end{array}$ \\
\hline \multicolumn{2}{|l|}{ Sex } \\
\hline Women & 1.00 \\
\hline Men & $0.90(0.80$ to 1.02$), p=0.1$ \\
\hline \multicolumn{2}{|l|}{ Calendar period } \\
\hline $1991-1995$ & 1.00 \\
\hline 1996-1999 & 0.88 (0.75 to 1.03 ) \\
\hline $2000-2003$ & $1.10(0.95$ to 1.27$), p=0.16^{*}$ \\
\hline \multicolumn{2}{|l|}{ Age group (years) } \\
\hline$<25$ & 1.00 \\
\hline $25-34.9$ & 11.56 (7.99 to 16.73 ) \\
\hline $35-44.9$ & 16.05 (11.19 to 23.02 ) \\
\hline $45-54.9$ & 16.57 (11.51 to 23.85$)$ \\
\hline $55-64.9$ & $12.80(8.80$ to 18.63$)$ \\
\hline $65-74.9$ & $9.34(6.26$ to 13.95$)$ \\
\hline $75-84.9$ & 4.26 (2.57 to 7.05$)$ \\
\hline$>85$ & $1.44(0.44$ to 4.71$), p<0.0001$ \\
\hline \multicolumn{2}{|l|}{ Region } \\
\hline North East & 0.97 (0.66 to 1.43 ) \\
\hline North West & $0.84(0.65$ to 1.09$)$ \\
\hline Yorkshire and Humber & $1.02(0.73$ to 1.43$)$ \\
\hline East Midlands & 1.09 (0.80 to 1.47$)$ \\
\hline West Midlands & $1.24(0.98$ to 1.57$)$ \\
\hline East & $1.05(0.81$ to 1.37$)$ \\
\hline London & $1.38(1.11$ to 1.70$)$ \\
\hline South East & 1.00 \\
\hline South West & $1.15(0.87$ to 1.51$)$ \\
\hline Northern Ireland & 1.84 (1.35 to 2.51 ) \\
\hline Wales & $1.16(0.88$ to 1.53$)$ \\
\hline Scotland & $1.16(0.86$ to 1.55$), p=0.0011$ \\
\hline \multicolumn{2}{|c|}{$\begin{array}{l}\text { All incidence rate ratios are mutually adjusted for all other } \\
\text { variables in the table. } \\
\text { *p for trend. }\end{array}$} \\
\hline
\end{tabular}

The main strength of our study is the large size of our cohorts, which means that we have been able to give precise estimates of disease incidence and to stratify our results by age, sex, region, and year. The main potential weakness of our study is the validity of the diagnoses of IPF and sarcoidosis. We have previously examined the validity of IPF diagnoses in a similar computerised general practice dataset and found this to be high. ${ }^{12}$ This is perhaps not unexpected, as it is unlikely that general practitioners would record diagnoses such as IPF or sarcoidosis in their records unless they have been confirmed by a hospital referral. Further reassurance about the validity of our disease diagnoses is given by the fact that our cases of IPF and sarcoidosis appear similar in terms of demographics to those

\begin{tabular}{|c|c|}
\hline & $\begin{array}{l}\text { Mutually adjusted hazard } \\
\text { ratios }(95 \% \mathrm{Cl})\end{array}$ \\
\hline \multicolumn{2}{|l|}{ Sex } \\
\hline Women & 1.00 \\
\hline Men & $1.52(0.96$ to 2.42$), p=0.08$ \\
\hline \multicolumn{2}{|c|}{ Calendar period } \\
\hline $1991-1995$ & 1.00 \\
\hline 1996-1999 & 1.21 (0.70 to 2.07 ) \\
\hline $2000-2003$ & $0.79(0.38$ to 1.63$), p=0.7^{*}$ \\
\hline \multicolumn{2}{|c|}{ Age group (years) } \\
\hline$<25$ & 1.00 \\
\hline $25-34.9$ & 0.25 (0.04 to 1.52 ) \\
\hline $35-44.9$ & $0.32(0.06$ to 1.57$)$ \\
\hline $45-54.9$ & $0.88(0.20$ to 3.90$)$ \\
\hline $55-64.9$ & $2.07(0.48$ to 8.96$)$ \\
\hline $65-74.9$ & 5.11 (1.19 to 21.96$)$ \\
\hline $75-84.9$ & 16.02 (3.57 to 71.90$)$ \\
\hline$>85$ & $9.90(0.87$ to 113.41$), p<0.0001$ \\
\hline \multicolumn{2}{|c|}{$\begin{array}{l}\text { All incidence rate ratios are mutually adjusted for all other } \\
\text { variables in the table. } \\
\text { *p for trend. }\end{array}$} \\
\hline
\end{tabular}


in other large studies, and the survival experience of our IPF cohort is similar to that reported for other cohorts..$^{6-8} 1314$

Another potential weakness of our study is that, despite our study design, some of our cases may actually be prevalent rather than incident cases. If this is the case, this error is unlikely to have had a major impact on the trends in disease incidence but might cause an overestimate of survival time since prevalent cases are, by definition, survivors and have a longer median survival length than incident cases. ${ }^{4}$ The fact that our results for survival for patients with IPF are similar to other estimates of survival suggests that any such misclassification is likely to be minor.

There are currently few data available on the incidence of interstitial lung disease in the UK with most estimates coming either from disease registries or, in the case of IPF, from death certificate registrations. In general, estimates of disease incidence from registry datasets may be overinflated because of the problem of accurately defining the denominator population, while estimates from death registrations are usually underestimates because the diagnosis is not included on the death certificate. The largest of the available interstitial lung disease registries is the New Mexico Interstitial Lung Disease registry which used a variety of methods to identify all cases of interstitial lung disease diagnosed in Bernillo County between 1988 and $1990 .^{8}$ This registry reported an incidence rate per 100000 person-years for IPF of 10.7 for men and 7.4 for women, and equivalent figures for sarcoidosis of 0.9 and 3.6. In an analysis of a private health maintenance organisation in Detroit, Rybicki et al estimated the incidence of sarcoidosis to be 9.6 per 100000 person-years in men and 12.1 per 100000 person years in women. ${ }^{9}$ We have previously analysed death registrations for IPF in the UK between 1979 and 1992 and found that the crude registered mortality rate for IPF increased from 0.7 to 1.7 per 100000 person-years. ${ }^{3}$ It has been shown that only about $60 \%$ of people known to have IPF have this diagnosis recorded on their death certificate ${ }^{2}$ and, with this in mind, it seems likely that the true death rate from IPF in the UK in 1992 was 2.8 per 100000 person-years, a figure which is very similar to the incidence value of 2.7 per 100000 person-years for the period 1991-1995 found in the present study. Our estimates of the current incidence of IPF and sarcoidosis in the UK are therefore consistent with the limited data available from previous studies.

We cannot be certain that the rapid increase observed in the incidence of IPF over time reflects a true increase in disease incidence or whether other explanations, such as an increase in case ascertainment or changes in disease recording, have a role. Ascertainment is a particularly important point to consider because the introduction of high resolution computed tomography in the early 1990s has had an important impact on the investigation and diagnosis of interstitial lung disease, particularly for IPF. In general, as the ascertainment of a disease increases, severity decreases because the additional cases tend to have milder disease. In our study, prognosis was not influenced by year of diagnosis, suggesting that either increased ascertainment was not a major factor in the observed increase in disease incidence or that at present ascertainment is still at an early stage and only a small proportion of cases of IPF are currently diagnosed. In addition, we cannot exclude the possibility of a bias resulting from an increased recording of IPF diagnoses in the general practice software, although the fact that no upward trend was observed for sarcoidosis argues against major changes in the way in which general practitioners use the software to record diagnoses of interstitial lung disease over time. Our previous studies of death certificate registration have also shown increases in the incidence of IPF over time of a similar magnitude to the current study. Taken together, the studies show a continue upward trend in the incidence of IPF between 1979 and 2003 which shows no sign of levelling off. ${ }^{2}$ Whether this increase is true, due to ascertainment, changes in disease recoding, or a combination of all of these factors is not known, but what is clear is that IPF needs to be recognised as an important cause of premature death in the UK with approximately 4000 cases being diagnosed each year. Our finding that the incidence of sarcoidosis has remained stable over time is consistent with data from the USA. ${ }^{9}$

The regional pattern in the incidence of IPF which we observed is different from a previous report of regional mortality from IPF, in which death rates were highest in the centre of the country and lower in the North. The reasons for this are not clear. ${ }^{2}$ The previous death certificate study was based on over 5000 deaths while our study was smaller with 920 cases. It is therefore possible that the difference between the studies is explained by random error arising from the relatively small number of cases in each region in the present study. Another possible explanation is the presence of regional differences in death certification. The high incidence of sarcoidosis in Northern Ireland, the West Midlands, and London may be explained by the ethnic make up of these populations, as it has previously been shown that sarcoidosis is more common in Irish and black ethnic groups, although we do not have patient level data on ethnicity to confirm this. ${ }^{15}$

In general, sarcoidosis is considered to have a good prognosis and, because patients with sarcoidosis tend to be young, deaths in this population are rare. Our findings show that patients with sarcoidosis do have an increased mortality rate compared with the general population in relative terms, but in absolute terms sarcoidosis does not cause many additional deaths. Although we do not have cause-specific mortality or detailed severity data, it seems possible that the excess deaths in the cohort of patients with sarcoidosis result from severe and complicated cases of the disease, reinforcing the need for clinical trials in patients with more severe disease.

In summary, IPF is becoming an increasingly important respiratory illness in the UK with approximately 4000 new cases being diagnosed each year in England and Wales. To put this into context in terms of disease burden, the equivalent figures for small cell lung cancer, mesothelioma, ovarian cancer, and kidney cancers are 6000, 1800, 5600, and 4300. It is clear that there is a pressing need for research into the causes and treatments of IPF, and development of specialised services for these patients. Sarcoidosis also represents an important work load for chest physicians with approximately 3000 new cases diagnosed each year in the UK. The increase in mortality associated with a diagnosis of sarcoidosis, although small in absolute terms, highlights the need for a better evidence base for the treatment of this condition.

\section{ACKNOWLEDGEMENTS}

The authors thank EPIC for their continued help and support in using THIN.
Authors' affiliations
J Gribbin, R B Hubbard, I Le Jeune, C J P Smith, J West, L J Tata, Division of Epidemiology and Public Health, University of Nottingham, Nottingham, UK
Funding: British Lung Foundation.
Competing interests: none.

\section{REFERENCES}
1 National Heart and Lung Institute. Respiratory disease. Report on problems, research approaches, needs, 73-432. Washington, DC: DHEW, 1972. 
2 Johnston I, Britton J, Kinnear W, et al. Rising mortality from cryptogenic fibrosing alveolitis. BMJ 1990;301:1017-21.

3 Hubbard R, Johnston I, Coultas DB, et al. Mortality rates from cryptogenic fibrosing alveolitis in seven countries. Thorax 1996;51:711-6.

4 Hubbard R, Johnston I, Britton J. Survival in patients with cryptogenic fibrosing alveolitis: a population based cohort study. Chest 1998; 113:396-400

5 Mapel DW, Hunt WC, Utton R, et al. Idiopathic pulmonary fibrosis: survival in population based and hospital based cohorts. Thorax 1998;53:469-76.

6 Schwartz DA, Helmers RA, Galvin JR, et al. Determinants of survival in idiopathic pulmonary fibrosis. Am J Respirat Crit Care Med 1994; 149:450-4.

7 Wells AU, Cullinan P, Hansell DM, et al. Fibrosing alveolitis associated with systemic sclerosis has a better prognosis than lone cryptogenic fibrosing alveolitis. Am J Respir Crit Care Med 1994;149:1583-90.

8 Coultas DB, Zumwalt RE, Black WC, et al. The epidemiology of interstitial lung diseases. Am J Respir Crit Care Med 1994;150:967-72.
9 Rybicki BA, Major M, Popovich J Jr, et al. Racial differences in sarcoidosis incidence: a 5-year study in a health maintenance organisation. Am J Epidemiol 1997; 145:234-41.

10 Bourke A, Dattani H, Robinson M. Feasibility study and methodology to create a quality-evaluated database of primary care data. Inform Prim Care 2004; 12:171-7.

11 Hubbard R, Lewis S, Richards K, et al. Occupational exposure to metal or wood dust and aetiology of cryptogenic fibrosing alveolitis. Lancet 1996;347:284-9.

12 Hubbard R, Venn A, Lewis S, et al. Lung cancer and cryptogenic fibrosing alveolitis: a population based cohort study. Am J Respir Crit Care Med 2000;161:5-8.

13 Baumgartner KB, Samet JM, Coultas DB, et al. Occupational and environmental risk factors for idiopathic pulmonary fibrosis: a multicenter case-control study. Am J Epidemiol 2000;152:307-15.

14 Baughman RP, Teirstein AS, Judson MA, et al. Clinical characteristics of patients in a case-control study of sarcoidosis. Am J Respir Crit Care Med 2001;164:1885-9. 15 Brennan NJ, Crean P, Long JP, et al. High prevalence of familial sarcoidosis in an Irish population. Thorax 1984;39:14-8.

\section{LUNG ALERT}

\section{Budesonide-formoterol reliever therapy in asthma}

$\Delta$ Rabe KF, Atienza T, Maqyar P, et al. Effect of budesonide in combination with formoterol for reliever therapy in asthma exacerbations: a randomised controlled, double-blind study. Lancet 2006;368:744-53

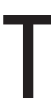
his 12 month study was conducted in patients with moderate to severe asthma who were symptomatic on regular budesonide-formoterol maintenance therapy. All 3394 patients enrolled had had at least one severe asthma attack in the year before entry, and were randomised to receive budesonide-formoterol maintenance therapy ( $160 \mu \mathrm{g}$ and $4.5 \mu \mathrm{g}$ ) plus one of three as needed therapies: budesonide-formoterol ( $160 \mu \mathrm{g}$ and $4.5 \mu \mathrm{g}$ ), formoterol $(4.5 \mu \mathrm{g})$ or terbutaline $(0.4 \mathrm{mg})$. The primary outcome measure was time to first severe exacerbation, which was defined as an exacerbation resulting in emergency treatment or hospitalisation or the need for treatment for more than 3 days with oral steroids.

Time to the first severe exacerbation was prolonged in the group using budesonideformoterol reliever therapy compared with either formoterol $(p=0.0048)$ or terbutaline $(p<0.0001)$ alone. The yearly rate of exacerbation per patient was reduced by $33 \%$ in the budesonide-formoterol group compared with the formoterol group $(\mathrm{p}<0.0001)$ and by $48 \%$ compared with the terbutaline group $(\mathrm{p}<0.0001)$. The number of days without symptoms or reliever use and lung function increased in all groups. The number of adverse events was similar across all three groups.

Although the mechanism underlying the reduction in exacerbations seen with the use of budesonide-formoterol as both maintenance and reliever therapy is not known, this combination reduces the risk of severe exacerbations compared with maintenance budesonide-formoterol plus either formoterol or terbutaline. However, as needed formoterol provided better exacerbation control than terbutaline, so part of this effect may be due to formoterol.

J K Quint

Clinical Research Fellow and Specialist Registrar, Royal Free and University College, London, UK; i.quint@medsch.ucl.ac.uk 